\title{
Diversity Monitor 2005: Diversity as a quality aspect of television in the Netherlands
}

\author{
JOYCE KOEMAN, ALLERD PEETERS, and LEEN D'HAENENS
}

\begin{abstract}
This article looks into the way in which public-service as well as commercial TV stations in the Netherlands assume their social responsibility towards a pluralist society. After all, television channels are expected to be 'mirrors of society'; the key question is then how successful their programs are in conveying a well-balanced representation of all groups in society. By means of a quantitative analysis, the Diversity Monitor charts the (re)presentation of different groups, with a particular focus on gender, age, and ethnicity. Apart from diversity, and as a subcomponent of the Quality Card (McKinsey, 2003), the Monitor also reviews innovation as an indicator of program quality. The results reveal a wide diversity of TV programs in the Netherlands, but diversity as such is no guarantee of a balanced (re)presentation of society at large. Due to selection mechanisms on the side of the broadcaster and the public, what the viewer eventually gets is at the most a mirror of his or her own group.
\end{abstract}

Keywords: social representation, public service broadcasting, cross-medial applications, (reflective) diversity

\section{Responsibility and quality of public broadcasting: Ideal and reality}

Many media researchers looking at media texts and into the portrayal of ethnic minorities are inspired by a variety of rhetorical and narrative methods as well as post-colonial and feminist theories. A central theoretical vision characterizing such content analysis is social constructivism, which is based on the assumption that words and pictures participate in the social creation of reality. In other words, discursive practices in society are vehicles for socially constructed knowledge and power (Berger and Luckmann, 1966). These discursive practices in the media do not merely reflect or represent social entities and relations, but they rather construct and 'constitute' them. Of course 'the' media do not exist and 
meanings evolve. Van Dijk's (1991; 1983) often-quoted work on racism in the Dutch media illustrates that media products are not only reflections of reality but they also help construct it. Prejudices are shaped subtly or clearly, and research is far from univocal here, according to the ways in which members of a group, e. g., ethnic minorities, are presented and framed in media messages. A recurrent, homogenizing trend when speaking about race and ethnicity is spotted through content analyses. Therefore, media makers must be careful when describing others in racial and ethnic terms, and when doing so, racial and ethnic diversities should be pointed at in an effort not to 'lump together' an entire group. Diversity can be looked at in terms of a variety of themes dealt with and viewpoints shared, or can be visualized in the rich composition of a cast paralleling more or less the audience groups targeted. Hence, the care for diversity can be considered a kind of 'virtuous' opposite for the practice of stereotypes and clichés.

Stereotypes are fixed expectations of what a particular group is like; they are often linked to external characteristics such as gender, ethnicity and age. Research has revealed the media's tendency towards stereotype images of women and ethnic minorities as well as young and old people. Women are often portrayed in care-giving roles (e. g., Kahn, 1996; Cook, Thomas and Wilcox, 1994). In the case of ethnic minorities it is mainly conflicts and menacing situations that are pulled into the foreground (e. g., Cottle, 2000; Ter Wal, 2002; Van Dijk, 1991). Older people are often shown as handicapped and dependent on medical care and as having limited capabilities and a rigid mental outlook (Smythe, 2003). Conversely, there is a growing trend to portray adolescents and children as self-reliant individuals, virtually on a par with adults (McKee, 2003). The biased and/or unbalanced representation in the media is apt to further the stereotyping of various groups (Cottle, 2000).

As television continues to dominate media use in Dutch society with an average viewing time of nearly 3.5 hours a day in 2004 (Peeters, Jager and Kalfs, 2005), notwithstanding ICT's increasing popularity, it follows that television has a demonstrable impact on how the public at large perceives the world and on the way individuals create an image of themselves and of others (Cole, 1981; Gibson, 1996; Cottle, 2000). Ideally, the media should therefore be mirrors of the pluralist society and should not in any way distort the image of whatever group. The creation of a certain image undoubtedly influences public opinion, if only because most people have little contact with other groups and so have to rely on what others believe to be true and on what the media put forward.

Television is an all-purpose medium: By offering different program formats (e.g., news, entertainment and commercials) it should meet the needs of a wide range of audiences. Therefore the public-service broad- 
casting system has multiple functions and responsibilities: it should provide the public with high-quality cultural and informative programs, especially during prime-time (see among others Souchon, 1994).

The full range of programs offered by the Dutch public-service broadcaster provides (at least for the time being) entertainment, opportunities for socialization, political awareness, education, a chance to escape reality, etc. However, the future of this wide range of programs remains uncertain in so far as the government emphasizes the informative function of the public channels and looks upon entertainment as a question of form rather than of content.

Under the terms of the Concessionary Act of 2000, the Dutch public broadcasting system takes its responsibility very seriously; its mission is to address all groups of society and to (re)present them in the most balanced fashion possible. The policy with which this mission is to be carried out highlights the broadcaster's public responsibility and goes beyond mere conformity with program regulations and financial criteria (see Bardoel, d'Haenens and Peeters, 2005). Still, the question remains in how far the audience-oriented programming policy of the public-service system is effectively more successful than the consumer-oriented approach of the commercial stations in reflecting the diversity of Dutch society. A further question then is: does the public system not quite succeed in achieving its goals or do the commercial stations manage to do so even without those specific guidelines?

\section{The Quality Card: The bridge between ideal and reality?}

It follows that we need measuring tools that guarantee pluralism and the presence of different viewpoints and voices in the media. Some intensive work has been done on the development and implementation of the Quality Card, an instrument measuring the quality of the public channels. External consultant McKinsey (2003) played a key role in designing the card. The Quality Card has eight indicators distributed over three dimensions: 1) distinctive and qualitative programming; 2) serving the society and the citizens of the Netherlands; 3 ) accountability in terms of the use of financial resources (see Figure 1). Especially the former two dimensions are relevant to the present study; financial effectiveness and efficiency have not been considered. In drawing up the eight indicators of the Quality Card allowance has been made for measurability and availability of data and research. The card is therefore mainly a tool to order and to interpret existing information.

Program quality, reliability, and innovation are the major indicators in the first dimension, i. e., the distinctive and qualitative aspect of programming. The concept 'program quality' distinguishes between func- 


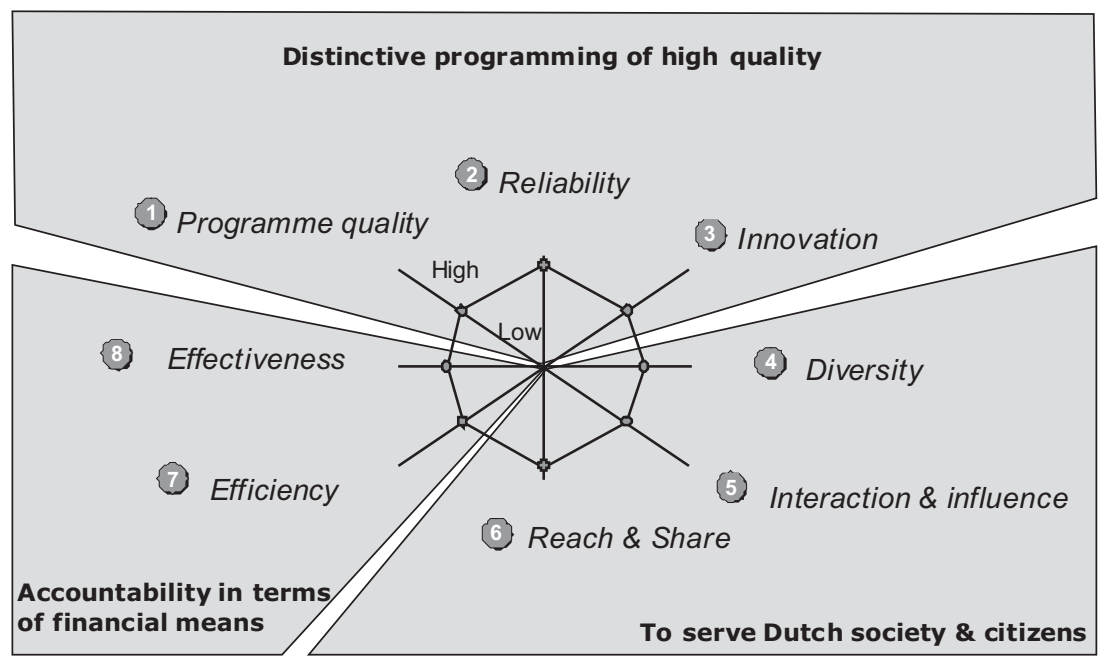

Figure 1. The eight performance measures of the Quality Card (McKinsey, 2003).

tional quality (the extent to which programs meet the public's preferences and expectations) and professional/traditional quality (quality according to the makers' standards). Functional quality is assessed by an Internet panel of 8,000 viewers on the basis of a set of pre-determined characteristics. The panel evaluates programs broadcast by public as well as commercial stations on the evening before; the panel also plays a major role in measuring the public's appreciation of innovation (e.g., new formats), interaction (e.g., cross-medial applications) and impact (e. g., the prominence of programs in articles and reviews published in the printed media) (Peeters, Jager, and Kalfs, 2005).

The second dimension comprises service to the citizens; it is defined by the indicators of diversity, interaction, and impact or reach. In measuring the interaction with and the impact on the public, the most important parameters are the image of the channel and the reactions of its audience. To assess if the public at large as well as specific target groups are reached, the viewing/listening/surfing behavior of the Dutch public and of specific groups is charted. For radio and television standardized measuring methods are available, but for surfing on the Internet it is necessary to further develop special indicators.

The diversity of program types is a major dimension in the performance of the television market (see McQuail, 1992). Next to freedom of expression and access to the media, diversity in the media is one of the pillars of Dutch media policy. However, diversity is also a very broad concept, one which emerges at two different levels: the availability of 
different sources and media and the diversity of media content (Van Cuilenburg, 2005).

To find out how diverse media content is, the distinction between open and reflective diversity is often made. 'Open diversity' looks at the extent to which different types of programs are presented in equal proportions. 'Reflective diversity' deals with the relation between supply and demand, i. e., it looks at the ratio between the types of programs broadcast by the channels and those actually viewed or listened to by the public (McQuail, 1992; Van Cuilenburg, 1999; Van der Wurff, 2004). Van der Wurff (2004) reveals how diversity in the Dutch television landscape decreased in the 1990s, although the number of programs offered to the public increased sharply. This of course implies that television offered more of the same. The results, however, suggest that Dutch audiences in general tend to prefer a diversity of programs. It is therefore up to the viewer himself to actively make a varied selection from a less diverse program offer.

Van der Wurff (2004) claims that open diversity (and to a lesser extent reflective diversity as well) would be considerably reduced should publicservice broadcasting suddenly disappear. Under the terms of its public mission, the public broadcasting system is expected to offer a more complete and more balanced range of programs than the commercial stations, though its programming might also turn out to be less popular. So far entertainment has always been an integral part of the programs of the public channels. However, as a result of cutbacks, of a smaller degree of government intervention and of far-reaching government plans suggested by the latest report of the Wetenschappelijke Raad voor Regeringsbeleid (Scientific Council for Government Policy, 2005) the Dutch public channels might stand to lose entertainment programs in the sense that they would keep entertainment only as a format and no longer as content. The entertainment function would then chiefly be assumed by the commercial stations, which is obviously to the detriment of the open diversity of the public channels.

\section{The Diversity Monitor: Methodological choices}

The Monitor Diversiteit 2002 (Sterk and Van Dijk, 2003) was used to measure how the public and commercial channels assume their social responsibility. It is the first time that the representation of ethnicity, gender, age and (visible) handicaps on Dutch television was charted using the following research questions:

1) Does Dutch television provide a representative image of social diversity? 
2) Is there any difference between the public and the commercial channels with regard to the share of men/women, young/old and native population/migrants?

The questions mainly focused on the visibility of talking individuals appearing in fiction as well as non-fiction programs and in programs produced by the channels themselves as well as in those they bought from other sources. What matters is not only whether given groups come on screen at all, but also how they are put on. For example: How are they addressed? What role or function do they have? With what topics are they associated? To what extent are ethnicity, men/women relations and age prominent topics?

The main conclusions of the Diversity Monitor 2002 showed that Dutch television did not reflect the social diversity in society. Especially the distribution of men and women was distorted, since only $35 \%$ of the actors on screen were women, while in reality there are slightly more women than men in society. Regarding ethnicity, white Europeans dominated the public and commercial television screens. But some differences between public and commercial channels should be looked at as well. Public channels portrayed Dutch minority groups such as Surinamese/ Antilleans, merely because they broadcasted 'homemade' fiction programs, while commercial channels mainly showed African Americans in US-made fiction programs. The television population also differed in age structure compared to Dutch society. Most actors were between 30 and 49 years old, while teenagers (13-18 years) and seniors $(65+)$ were hardly present.

From the very beginning it was the explicit intention to repeat the assessment at a later stage so that the Monitor could be used in future as an instrument of policy-making. For this reason the study was carried out again three years later (Monitor Diversiteit 2005). This time the public-service broadcasting system entrusted the project to the department of Communication of the Radboud University Nijmegen (The Netherlands) and the Center for Media Culture and Communication Technology (CMC) of the Catholic University of Leuven (Belgium).

If a comparison between the Monitor 2002 and the Monitor 2005 was to be made, the key questions had to be the same, although there were some modifications and additions. The two research questions mentioned above remained and were complemented by the Monitor 2005 in several respects.

$\vartheta$ The Diversity Monitor 2002 only aimed to measure quality in terms of diversity, whereas the 2005 Monitor adds a second aspect of quality, namely, innovation (see, among others, a presentation of the McKinsey Quality Card by Bardoel, d'Haenens and Peeters, 2005). Furthermore, a 
third key question was added in order to widen the scope of the Monitor so that it also looks into the use of cross-medial applications in television programs (Van Selm and Peeters, 2005):

3) What cross-medial applications do public and commercial stations use in their different types of programs?

The additional questions on cross-medial applications are meant to shed light on references to other media (e.g., text messages, websites, e-mail addresses, telephone numbers, and teletext) and on the prominence and frequency of these innovative elements in programs. In so doing it hopes to obtain information on the kinds of programs in which these new elements occur, on the position they have in the program, on the group of viewers they aim at and on the purpose they serve.

The three questions quoted above are designed to tell us more about the concept 'open diversity' since they describe the diversity of individuals appearing on screen (diversity on given channels and in given program formats, but also diversity when channels and program formats are compared). However, it was also felt necessary to look into 'reflective diversity'; to this end the results of the Monitor 2005 were coupled to the ratings of the various channels and programs by means of a fourth research question:

4) What links are there between the viewing habits of different groups and the individuals and characters appearing in given television programs?

The linkage of ratings to the Diversity Monitor 2005 enables us to assess various elements, for instance the attraction that the cast or the presence of given individuals in particular programs has on men/women or younger/older viewers.

\section{The 2005 sample}

The Diversity Monitor 2005 analyses a total of nine Dutch television channels, among which three public channels (Nederland 1, 2 and 3) and six commercial channels (RTL4, RTL5, Yorin, SBS6, Net5, and Veron$i c a)$. These were all the Dutch general interest channels at the time and together they reached a market share of $89 \%{ }^{1}$. In comparison with the 2002 Monitor, the channel, V8 has been succeeded by Veronica and Z@ppelin is no longer considered a station in its own right but rather as a part of Nederland 3. For all these channels a constructed week has been examined (every six days); the seven working days are spread over 
Table 1. Amount of fiction and non-fiction programs by channel.

\begin{tabular}{lccc}
\hline Channel & Non-fiction & Fiction & Total \\
\hline Nederland 1 & 67 & 4 & 71 \\
Nederland 2 & 60 & 8 & 68 \\
Nederland 3 & 74 & 37 & 111 \\
Public & 201 & 49 & 250 \\
RTL 4 & 40 & 9 & 49 \\
RTL 5 & 18 & 21 & 39 \\
Yorin & 23 & 11 & 34 \\
SBS 6 & 40 & 6 & 46 \\
Net5 & 5 & 25 & 30 \\
Veronica & 16 & 89 & 33 \\
Commercial & 142 & 138 & 231 \\
\hline Total & 343 & & 481 \\
\hline
\end{tabular}

the period from Monday, February 28, up to and including Tuesday, April 5, 2005 (slightly more than 5 weeks). This was done in order to reduce the risk of current events influencing the data.

Only prime-time programs were included in the sample, since $76 \%$ of the total viewing time was spent between 18:00 hrs and 24:00 hrs (audience measurement among six-year-olds and above in 2005). As soon as more than half of a program fell within the period concerned, it was included in the selection. Hence, the sample is both a representative and manageable selection of public and commercial programs.

All the evening programs of the three public-service channels were included in the sample. It was, however, necessary to limit the total number of hours to be coded to about 100 hours; to this end about onethird of the programs were removed from the sample in an a-select fashion. That is, for each day one period per broadcast organization (18:0020:00 hrs, 20:00-22:00 hrs or 22:00-24:00 hrs) was chosen at random, though with the following restriction: Across the entire constructed week, each period (the first, second or third period) could be removed at least twice and at the most three times per channel; moreover, the same period could not be omitted on a Saturday and on the following Sunday.

The final sample consisted of 104 hours of public-service programs and 124 hours of commercial programs. These are net figures, i. e., excluding commercials, program announcements, and programs that had less than half of their broadcast time in the periods mentioned above. The number of programs analyzed amounts to 481, with 250 aired on the public channels and 231 on the commercial channels (Table 1). These 
programs are predominantly non-fiction $(71 \%)$. The commercial channels offer, relatively speaking, more fiction, especially because of the input of RLT5 and Net5.

\section{Structure of the coding instrument}

The questions examined in the Monitor 2005 were made operational in a coding instrument which largely resembles that of the 2002 Monitor. The structure of the coding instrument has been preserved as well, which makes three different levels of analysis possible (the general program level, the level of items in non-fiction and the level of actors).

The first part gives each program a unique identification code and registers the main characteristics of the program, such as the title, the genre, and intended audience. Also questions about cross-medial applications can be considered as part of this general level of program analysis. The distinction made here between fiction or non-fiction programs affects the encoding process explained below.

Since a sample of 228 hours of television obviously holds a vast potential of data and it is next to impossible to code all individuals who come on the screen, the second part of the coding instrument focuses on 'talking individuals' mainly (for silent individuals or groups on screen, only gender and ethnicity were coded). Moreover, the number of individuals/ characters to be coded also needed to be limited, thus in non-fiction programs a distinction was made between presenters and other talking persons. For each non-fiction program we applied a maximum of five presenters and ten subjects, with a maximum of twenty persons per subject ${ }^{2}$. In fiction programs, of course, we deal with characters only and the number of characters coded depends on the length of the program. In programs with a length of less than 25 minutes two principal characters and two supporting roles were coded; in longer programs four principal roles and two supporting roles (in order of appearance).

\section{Measuring gender, age, and ethnicity}

The code book measured eleven characteristics of all talking individuals, in both fiction and non-fiction programs: gender, age, ethnicity, language, accent, marital status, etc. The present analysis is mainly concerned with gender, age, and ethnic origin. The biological body served as reference point for the determination of gender. With respect to the ratio of men to women, it seemed logical to assume a ratio of $50: 50$, as a reflection of Dutch population ratios. The coding staff estimated the age of individuals and characters by means of a classification into six categories: children ( 0 up to and including 12), teenagers (13 to 18), 
young adults (19 to 29 ), adults (30 to 49 ), middle-aged people (50 to 64 ) and seniors ( 65 and above).

The ethnic origin of individuals and characters proved to be the most difficult variable to estimate visually, because television images offer few unambiguous leads. When trying to quantify ethnicity, one tends to quickly get lost in a tangle of identity definitions; i.e., there are the definitions of identity used in official policies and there are the identities we give ourselves, identities can be imposed and they can be attributed, and there is visibility. A widely accepted definition of the concept 'migrant' is that used by the social-cultural planning office (SCP, Sociaal Cultureel Planbureau) and the statistics office (CBS, Centraal Bureau van de Statistiek): It considers people as members of the ethnic minorities, i.e., as migrants, if they were born abroad or if at least one of their parents was born abroad. They make up $19 \%$ of the population and can be classified into two generations: the first generation concerns those who were born abroad, the second those who were born in the Netherlands. The CBS also distinguishes between Western (8.6\%) and nonWestern $(10.4 \%)$ migrants.

Since it is impossible to ascertain where all the people appearing on screen were born, and since we often know even less about the birth place of their parents, the Monitor resorts to a definition on the basis of visibility in the wide sense. Biological physical characteristics are of primary importance, that is, the color of their skin, type of hair, and shape of their eyes. In the second place we have cultural characteristics; i. e., clothing, name and accent. Ethnic descent can become clear through definition by the media maker as well as through self-definition in the course of the program when an individual states his or her identity, e. g., when a seemingly native Dutch person talks about his or her non-Dutch background. Although all these considerations helped to make the concept 'ethnicity' operational, we have no unambiguous criterion that we can use as a demographic basis for determining the presence of ethnic minorities in the media is representative of their presence in Dutch society.

The coding work was carried out by 26 third and fourth-year students in communication science of the University of Leuven (Belgium). They were organized in eleven pairs, one group of three and one individual. Just like in 2002 there was a heavy emphasis on coders working together, the whole group having taken a training course in order to enhance the reliability of their work. The training included a presentation of the purpose of the Monitor, an extensive discussion of the code book and the categories and codes to be attributed, and finally the effective use of the code book. A number of questions in the Monitor relate to aspects which are quite well-defined (genre of the program, channel, title, etc.) or which 
are simple enough to detect (function of the program, composition of the cast). The inter-coder reliability (Scott's pi) at the level of program characteristics is, for example, 0.99. Nevertheless all the variables were extensively reviewed. Particular emphasis was placed on the coding of the more complex variables such as ethnicity, age, and accent (northern or southern Dutch). In an effort to achieve the greatest possible consensus among the coders, numerous examples were given, the group also practiced using the coding instrument, and doubts about the accent were discussed with the two native Dutch coordinators. This resulted in rather satisfactory reliability measures for more complex variables such as ethnicity (Scott's pi $=.68$ ).

\section{Results of the Diversity Monitor 2005}

\section{Public against commercial: An initial impression}

After analyzing the more than 5,000 encoded individuals of our sample, it is fair to say that, generally speaking, Dutch television is dominated by men; two-thirds of all talking persons (presenters, individuals in nonfiction and characters in fiction) are men. It is a ratio which applies to public as well as to commercial channels (Table 2), but this is a superficial resemblance for the channels do differ on this point: Nederland 2, for instance, has numerous sports programs, reducing the number of women on the public channels to $25 \%$. The commercial channel Net5, however, concentrates on 'the young woman of the world' 3 attracting a high percentage of women; not surprisingly, the majority of its 'talking persons' is female $(54.6 \%)$.

The man/woman ratio on Dutch television, consequently, does not correspond with the composition of the Dutch population. Moreover, there is no correspondence either with regard to age (Table 2): here again television is not the mirror of society. Children $(\leq 12)$ and adolescents $(13-19)$ as well as senior citizens $(\geq 65)$ are clearly underrepresented although the public channels spend more attention on the seniors than their commercial counterparts. The largest group on television is adults between the ages of 30 and 50, who account for half of the people talking on screen. The group of young adults $(20-29)$ ranks second, and they are the main focus of the commercial channels.

When combining age with gender, we find that in all age brackets the number of men is larger than that of women. Women apparently stand the best chance of coming on screen if they are young adults or teenagers, whereas middle-aged women stand the smallest chance.

As in the Diversity Monitor reported on in 2002, the distribution on the basis of ethnic origin is strongly biased. Eight out of ten persons on 
Table 2. Distribution of gender, age and ethnicity in public and commercial programs (in percentages).

\begin{tabular}{|c|c|c|c|c|}
\hline & $\begin{array}{l}\text { Public } \\
(\mathrm{N}=2869)\end{array}$ & $\begin{array}{l}\text { Commercial } \\
(\mathrm{N}=2355)\end{array}$ & $\begin{array}{l}\text { Total } \\
(\mathrm{N}=5224)\end{array}$ & $\begin{array}{l}\text { CBS } \\
(\mathrm{N}=16,305.526)\end{array}$ \\
\hline \multicolumn{5}{|l|}{ Gender } \\
\hline Male & 67.7 & 66.3 & 67.1 & 49.5 \\
\hline Female & 32.3 & 33.7 & 32.9 & 50.5 \\
\hline \multicolumn{5}{|l|}{ Age $^{* * *}$} \\
\hline Children $(\leq 12)$ & 4.7 & 4.7 & 4.7 & 24.5 \\
\hline Teens $(13-19)$ & 4.1 & 2.6 & 3.4 & \\
\hline Young adults (20-29) & 18.7 & 24.0 & 21.1 & 61.5 \\
\hline Adults (30-49) & 49.0 & 52.5 & 50.6 & \\
\hline Middle aged (50-64) & 16.7 & 14.6 & 15.7 & 14.0 \\
\hline Seniors $(\geq 65)$ & 6.8 & 1.7 & 4.5 & \\
\hline \multicolumn{5}{|l|}{ Ethnicity**** } \\
\hline Whites & 80.5 & 82.8 & 81.5 & \\
\hline Native Americans & 1.0 & 1.4 & 1.2 & \\
\hline Blacks & 2.5 & 4.3 & 3.3 & \\
\hline Mediterranean & 4.6 & 2.3 & 3.6 & \\
\hline Asian & 2.9 & 1.3 & 2.2 & \\
\hline Other/unknown & 8.5 & 7.9 & 8.2 & \\
\hline
\end{tabular}

Note 1: The CBS uses other classifications of age and definitions of ethnicity; hence only gender and 3 age categories are comparable to the results of this Diversity Monitor.

Note 2: $* * *$ Significant difference at the .001 level (2-tailed).

Dutch television is classified as 'white', two out of ten as 'non-white'. In the latter category we find slightly more people of Mediterranean and Asian descent on public channels, whereas commercial channels have a slightly larger percentage of people with a darker skin. The reason for this difference is that commercial channels have a larger number of American films and series, in which African Americans are more numerous.

$\vartheta$ It is unfortunate that these ethnic ratios cannot be compared with the composition of the Dutch population. The Monitor relies on criteria of visibility, which are inconsistent with the definitions used in population statistics. Self-definition (or definition by the producers of the program) is relatively rare, so that the coders had to go by the verbal and physical characteristics of the persons talking. It is hard to determine ethnicity, as witnessed by the fact that $8.7 \%$ of all cases were classified as 'different/unknown'. Physical characteristics do of course play a very important role in determining ethnic origin, but even more often it is the combination of physical appearance and an individual's way of talking which enables us to make a classification in 'color groups'. 
For this reason a fourth element was analyzed, apart from gender, age and ethnic origin, namely the language and the accent of the individual concerned. It is striking to find that Dutch is more often heard on the public-service channels $(87.1 \%)$ than on commercial channels $(65.3 \%)$. The language commonly used in children's programs and in sports programs is Dutch, but in fiction English is more common. This is no surprise since the public channels have a larger number of Dutch productions and productions of their own, while their commercial rivals have more foreign productions, especially in the category of fiction.

This initial batch of results does not exactly create the impression that the public-service broadcaster is a textbook example of diversity on television. It is clear enough, however, that it no easy matter to pronounce on the public-service system and the commercial channels as a whole. We have to distinguish among different channels, program genres, subjects, and the functions or roles in which different groups or individuals appear. In the following sections we will try to sketch a more qualified picture of diversity on television so that a comparison between public television and commercial television does make sense.

\section{Diversity in different genres}

Differences in programming are even more significant than differences between channels. The genre of program, its format, and origin influence the content of a program quite strongly and make the comparison of channels more concrete.

Generally speaking, the bulk of prime-time television in the Netherlands consists of informative and educational items $(59.8 \%)$. Such programs are not the exclusive fare offered by the public channels, for RTL4 and $S B S 6$ also devote $51.0 \%$ and $52.2 \%$, respectively, of their programs to news and current affairs. In addition, the public channels, especially Nederland 3, offer a fairly large amount of entertainment $(19.5 \%)$ and programs for children, even in the evening $(11.6 \%)$. The commercial sector puts a greater emphasis on fiction, particularly foreign fiction $(20.2 \%)$.

Table 3 presents a survey of the diversity features in the individuals appearing in the different genres. We notice the distortion in the man/ woman ratio in all genres and particularly in sports programs, where women account for an exceptionally poor $7.1 \%$. Women are found mainly in entertainment, fiction, and children's programs, and this applies to public as well as commercial channels. What is most conspicuous, however, is the strong presence of women in fiction on the commercial channels, so much so that in the fiction on Net5 they even make up a majority. 
Table 3. Diversity characteristics by program genre (in percentages) for public and commercial channels together.

\begin{tabular}{|c|c|c|c|c|c|c|}
\hline & $\begin{array}{l}\begin{array}{l}\text { Enter- } \\
\text { tainment }\end{array} \\
(\mathrm{N}=861)\end{array}$ & $(\mathrm{N}=592)$ & $\begin{array}{l}\text { Informa- } \\
\text { tion/ } \\
\text { Education } \\
(\mathrm{N}=3081)\end{array}$ & $(\mathrm{N}=322)$ & $(\mathrm{N}=368)$ & $(\mathrm{N}=5224)$ \\
\hline \multicolumn{7}{|l|}{ Gender*** } \\
\hline Male & 58.3 & 58.4 & 68.5 & 62.7 & 92.9 & 67.1 \\
\hline Female & 41.7 & 41.6 & 31.5 & 37.3 & 7.1 & 32.9 \\
\hline \multicolumn{7}{|l|}{$\operatorname{Age}^{* * *}$} \\
\hline Children $(\leq 12)$ & 12.4 & 3.6 & 1.6 & 18.4 & 0.3 & 4.7 \\
\hline Teens $(13-19)$ & 2.4 & 3.9 & 3.7 & 5.8 & 1.0 & 3.4 \\
\hline $\begin{array}{l}\text { Young adults } \\
\quad(20-29)\end{array}$ & 33.1 & 24.8 & 16.3 & 18.4 & 26.9 & 21.1 \\
\hline Adults $(30-49)$ & 43.5 & 56.7 & 51.8 & 45.2 & 52.4 & 50.6 \\
\hline $\begin{array}{l}\text { Middle Aged } \\
\quad(50-64)\end{array}$ & 7.0 & 9.7 & 20.2 & 8.5 & 17.8 & 15.7 \\
\hline Seniors $(\geq 65)$ & 1.7 & 1.4 & 6.4 & 3.7 & 1.6 & 4.5 \\
\hline \multicolumn{7}{|l|}{ Ethnicity**** } \\
\hline Whites & 90.8 & 83.8 & 79.9 & 74.4 & 75.5 & 81.5 \\
\hline Native Americans & 1.3 & 3.4 & 0.9 & 0.9 & 0.3 & 1.2 \\
\hline Blacks & 2.9 & 10.0 & 2.2 & 3.6 & 2.4 & 3.3 \\
\hline Mediterranean & 1.9 & 0.5 & 4.5 & 5.1 & 3.3 & 3.6 \\
\hline Asian & 1.2 & 1.4 & 2.6 & 2.7 & 2.4 & 2.2 \\
\hline Other/unknown & 2.0 & 1.0 & 9.9 & 13.3 & 16.0 & 8.2 \\
\hline
\end{tabular}

Note: ${ }^{* * *}$ Significant difference at the .001 level (2-tailed)

With respect to the criterion of age, it is the children's programs (in our sample these are shown in prime time on Nederland 3 only) which come closest to the age structure of the Dutch population and which are therefore the most representative genre. Of the young people appearing in children's programs, $24.2 \%$ are younger than 19 . Young adults are found most in sports and entertainment programs and senior citizens $(50+)$ in informative and educational items. The largest group with respect to age are the adults between 30 and $50(50.6 \%)$, who represent a vast majority in fiction.

Turning to the measure of ethnicity, especially entertainment programs on both the public as well as commercial stations which, with an average of $90.8 \%$ white people, are rather 'white'. Children's and sports programs show more diversity of color, although there is often a good deal of vagueness about the ethnic origin of a person or character. In children's programs this lack of clarity can be partly explained by the presence of fantasty figures, puppets and animated models of which it is 
hard to determine ethnic origin. With respect to ethnicity in the various genres there are few differences between commercial and public channels. The informative and educational programs of the public channels are the only ones that are slightly more colorful.

\section{Different persons in different stories}

Diversity within each genre (and this goes for the public as well as the commercial channels) does not imply that there is also diversity in the way groups and individuals are represented. Consequently, if we want to understand how Dutch television represents groups and individuals and how images are created, we have to examine the prominence given to particular groups, what functions they have and what subjects they are associated with. In this context it may make sense to distinguish presenters, individuals (in non-fiction) and characters (in fiction), since these categories of persons cannot be assessed in exactly the same fashion.

About two thirds of all persons appearing on screen are men, but if women are present as well they are given the floor (i.e., get the opportunity to speak) as often as the men, both on public and commercial channels. The number of times any given person has the floor is evidence of the prominence he or she has in the program. Of even greater interest is the role which somebody has in a program or the function he or she has in the outside world. In television programs women (13.9\%), rather than men $(6.8 \%)$, prove to speak from the viewpoint of the common citizen. In contrast, men are more often $(11.6 \%)$ than women $(4.9 \%)$ cast as experts or spokespersons. In doing so men are more often than women expected to speak on behalf of others or of their own group.

In this way the old stereotype image of men and women is upheld by the public and commercial channels; i. e., men are given 'hard' functions and roles, while women are assigned 'soft' ones. The two groups of channels display the same tendency: Men more often appear as politicians, sportsmen, businessmen, policemen, or firemen, and women mainly as citizens, students, artists, mothers, and housewives.

The subjects of non-fiction programs underline these role patterns; i. e., only if the subjects concern upbringing, family, and relationships do women have a majority (53.2\%); in all other subjects it is men who dominate. In addition, women are found more than the average $(>32.3 \%)$ in items dealing with health, science and education, social affairs, religion, art and culture, and entertainment. A striking finding is that the public channels do not associate women solely with traditional subjects; women are given a say on very diverse topics, more so than in commercial programs. Conversely, the commercial channels present 


\section{Joyce Koeman, Allerd Peeters and Leen d'Haenens}

women more often than the public channels do when the following topics are discussed: recreation, hobbies, home and garden, the weather, and economic subjects. Unfortunately our current quantitative analysis does not allow us to determine whether these programs present women in a positive or negative light. Hence, we have planned a qualitative follow-up study looking into the argumentations adopted.

In fiction programs women also appear less often than men, but their chances of having a principal role are the same. We find, furthermore, that they have approximately the same functions as in non-fiction, with the understanding that fiction programs less often portray politicians, sportsmen or sportswomen, and businessmen or businesswomen.

In spite of young people as well as older people being generally underrepresented, it is worth finding out with what subjects and themes they are associated. To this end we examine the groups of young adults and over-50s. Most young people are found topics concerning art, culture and entertainment, a very broad category which includes many wellknown Dutch people. In addition, young adults are also numerous in sports programs. The seniors, for their part, appear in diverse subjects, in art, culture and entertainment and mainly in politics. In fiction programs young people often talk about relationships and older people about work, which is often for many seniors their main activity.

An examination of the relation between ethnicity and the appearance of individuals in given programs produces a striking finding. More than half of the white people $(55.7 \%)$ appearing on screen take the floor several times or regularly or even often, while most non-white individuals $(56.9 \%)$ are given only one chance to speak. Yet migrants are not more explicitly presented as spokespersons for their 'own' group than individuals belonging to the native population. Just like the young and the seniors, the non-white group is strongest in subjects related to art, culture and entertainment (18.3\%). Apart from these three subjects they are mainly associated with the multi-cultural society (11.7\%) and terrorism and war $(10.7 \%)$. The public-service channel in particular mainly highlights migrants in the context of the multi-cultural society and integration. The commercial channels, by contrast, present non-white people mainly in programs dealing with art, culture, and entertainment. In fiction programs the main activities of white as well as of non-white characters mainly involve work, or they are distributed across work and home.

In $91.5 \%$ of the non-fiction programs there are one or more presenters, which form a distinct group among the encoded actors; they are predominantly men, generally in the age bracket of the (young) adults. If a woman acts as presenter, she is generally the chief presenter of the program, not the second or third presenter. The public and commercial channels adopt a comparable man/woman ratio on this point. The 
number of times that a presenter is actually speaking is comparable for men and women, but the functions they fulfill are not.

The coding instrument discerned various functions of presenters, representing different socio-demographics. Presenters usually play the role of presenters as such, or they are emcees, news-readers or do voice-overs. Most of the time these functions are filled by men, and the voice-over is nearly always done by men. A considerable number of women are newsreaders, especially on commercial channels. But the public channels employ more non-white news-readers, interviewers and emcees. Actually, non-white presenters prove to speak less often than their white colleagues.

\section{Specific groups in the limelight}

Generally speaking, the public channels as well as their commercial rivals rarely refer to specific groups such as women, young or old people or ethnic minorities in prime-time non-fiction programs. Nine out of ten non-fiction programs do not specifically speak with or about these groups; apart from the speakers, who are encoded, these groups hardly ever appear on screen. In spite of the few references to them, a trend is noticeable on the public channel to give some attention to these different groups (women, ethnic minorities and younger and older people), at least more prominently than the commercial channels do. In 2002 and 2005 we have found similar results for women (respectively $35 \%$ and $32 \%$ ) and ethnic minorities (respectively $12 \%$ and $11 \%$ ) on public television and a more balanced age distribution than on commercial channels. Especially Nederland 3 still proves to have an eye for these social groups. Here again, mainly children's programs heed the diversity in Dutch society by speaking of ethnic minorities, younger and older people, and women, thus reflecting the findings with respect to the characteristics of talking individuals in different genres.

The number of disparaging remarks that we find in the sample is (fortunately) small. Consequently we can give no more than a general indication about the persons who make such insulting or offensive remarks and about the victims. It is predominantly white men who speak disparagingly about others, and women and migrants are the chief butts. A qualitative follow-up study is expected to shed more light on the nature of these remarks, taking into account the type of program, e. g., a cabaret show in which offensive remarks are made in a humorous vein.

\section{How is diversity looked at?}

Van der Wurff (2004) claims that Dutch audiences seek diversity in the composition of their media menu. It may be true that Dutch viewers 
Table 4. Correlations between percentages of the program content and the viewers' gender and age.

\begin{tabular}{|c|c|c|}
\hline & Audience & \\
\hline Gender & $\%$ Female & $\%$ Male \\
\hline$\%$ female presenters $* * *$ & .22 & -.22 \\
\hline$\%$ female individuals (non-fiction) ${ }^{* * *}$ & .34 & -.34 \\
\hline$\%$ female characters (fiction) & .10 & -.10 \\
\hline Age & $\%$ Young & $\%$ Senior \\
\hline$\%$ young presenters $* * *$ & .33 & .33 \\
\hline$\%$ young individuals (non-fiction)*** & .28 & -.22 \\
\hline$\%$ young characters (fiction) & -.04 & .05 \\
\hline$\%$ senior presenters & -.08 & .07 \\
\hline$\%$ senior individuals (non-fiction) $* * *$ & -.23 & .23 \\
\hline$\%$ senior characters (fiction)** & -.24 & .24 \\
\hline
\end{tabular}

Note: Only genres with significant correlations are presented:

* Correlation is significant at the .05 level (2-tailed).

** Correlation is significant at the .01 level (2-tailed).

$* * *$ Correlation is significant at the .001 level (2-tailed).

make a varied selection of programs and switch, for example, from news to entertainment and drama, but that does not mean that by doing so they come face to face with diverse social groups. If diversity on television is linked to the few ratings which are available, what we find is that the preference of the public is for programs with and about their own group; i. e., young people select (foreign) programs in which adolescents and young adults are the key figures, and they do not watch programs featuring over-50s, while men tend to pass over programs in which women are well- represented (see Table 4).

Due to the combination of our content analysis with continuous audience measurement figures of the programs under study, we were able to assess the demographic composition of the audience in terms of age and gender. Table 4 reveals that for non-fiction programs the composition of the audience (i. e., percentage of women) correlates with the gender of the presenters (i. e., percentage of women in the presenters' team) as well as with the gender of the other actors figuring in the program (i.e., percentage of women in the items dealt with). When it comes to fiction programs, however, the amount of female viewers does not significantly correlate with the percentage of female actors. Table 5 also shows the correlations in terms of age; young audiences have a tendency to equally watch young presenters and youngsters in non-fiction programs, which seniors clearly have not. Furthermore, while young people do not seem 
to watch seniors (not in fiction nor in non-fiction), seniors do watch their age group both in fiction and non-fiction.

Generally speaking, based upon a full year of TV output (Van Cuilenburg, 2005), public channels tend to have a better record as far as open diversity is concerned, while from the point of view of reflective diversity the commercial channels do a better job. Based upon our calculations, Table 5 shows that older people are more in evidence on the public channels, except in information and educational programs. In general in public television fiction programs, seniors are relatively underrepresented and evidently in competition with numerous younger actors, except for a few striking examples in homemade fiction programs (e.g., Toen was geluk heel gewoon; Kinderen geen bezwaar) attracting a lot of viewers. Public channels tend to be more 'colored' than their commercial counterparts, but we find this feature particularly in programs with many other (white) persons or in programs with a relatively low number of viewers, as well as in children's programs (see also Table 5).

Table 5 provides per program genre the percentage of women, youths, seniors, and ethnic minorities as present on the screens of both the public and commercial TV channels under scrutiny. This time the percentages were calculated, accounting for exposure: i. e. the extent to which viewers are confronted with these actors on screen, meaning that a program weighs heavier in the calculation the more people are watching, the longer it takes, and the more people on screen (i. e. a person on screen weighs less in proportion to the amount of people on screen). Such exposure figures demonstrate the de facto diversity, which is comparable with reflective diversity. The commercial TV channels seem to remedy the relative lack of visibility of seniors and people of color in information and educational programs as these groups tend to be, on average, slightly better presented in this program genre.

The above are merely a few indications illustrating that high diversity at the level of programming does not necessarily mean that the audience meets a great diversity of people. Furthermore, research undertaken by Huysmans et al. (2004: 77) shows that the programming of the commercial channels is evolving towards more open diversity while there is a parallel trend in the public channels towards more reflective diversity. Indeed, if programs are roughly subdivided into informative and entertaining items, we find that, since the early 1990s, the number of informative programs on the commercial channels has risen relatively more sharply than their entertainment programs. Concurrently, the viewing time spent on informative programs has quadrupled while the time spent on entertainment items has merely doubled - a development contrary to general expectations. Television is therefore not a mirror of society 
Table 5. Weighed correlations on reflective diversity.

\begin{tabular}{|c|c|c|c|c|c|}
\hline & & Women & $\begin{array}{l}\text { Young } \\
(<29)\end{array}$ & $\begin{array}{l}\text { Senior } \\
(\geq 50)\end{array}$ & $\begin{array}{l}\text { 'Non- } \\
\text { white' }\end{array}$ \\
\hline \multicolumn{6}{|l|}{ Public programs } \\
\hline All & $\begin{array}{l}\text { - } \% \text { of actors } \\
\text { - Viewing share } \\
(\geq 6 \text { years old })\end{array}$ & $\begin{array}{r}.030 \\
-.095\end{array}$ & $\begin{array}{l}-.128 * \\
-.169 * *\end{array}$ & $\begin{array}{r}.183^{*} \\
-.162^{*}\end{array}$ & $\begin{array}{l}-.013 \\
-.093\end{array}$ \\
\hline Fiction & $\begin{array}{l}\text { - } \% \text { of actors } \\
\text { - Viewing share } \\
(\geq 6 \text { years old })\end{array}$ & $\begin{array}{l}-.040 \\
-.503\end{array}$ & $\begin{array}{c}.058 \\
-.567^{*}\end{array}$ & $\begin{array}{c}-.602 * \\
.933 * *\end{array}$ & $\begin{array}{r}.110 \\
-.220\end{array}$ \\
\hline Information/education & $\begin{array}{l}\text { - } \% \text { of actors } \\
\text { - Program length } \\
\text { - Viewing share } \\
\text { ( } \geq 6 \text { years old })\end{array}$ & $\begin{array}{l}-.026 \\
.190^{*} \\
-.110\end{array}$ & $\begin{array}{l}-.067 \\
-.070 \\
-.270 * *\end{array}$ & $\begin{array}{l}-.217^{*} \\
.264^{* *} \\
.174\end{array}$ & $\begin{array}{l}-212^{*} \\
-.177 \\
-.165\end{array}$ \\
\hline Children & $\begin{array}{l}\text { - } \% \text { of actors } \\
\text { - Program length } \\
\text { - Viewing share } \\
\text { ( } \geq 6 \text { years old) }\end{array}$ & $\begin{array}{l}.254 \\
.304^{*} \\
.272^{*}\end{array}$ & $\begin{array}{l}.187 \\
.105 \\
.300^{*}\end{array}$ & $\begin{aligned} & .131 \\
& .359^{* *} \\
&-.025\end{aligned}$ & $\begin{array}{l}.533^{* *} \\
.298^{*} \\
.369^{* *}\end{array}$ \\
\hline \multicolumn{6}{|l|}{ Commercial programs } \\
\hline$\overline{A l l}$ & - $\%$ of actors & -.047 & .058 & $.143^{*}$ & -.043 \\
\hline Informationleducation & $\begin{array}{l}\text { - } \% \text { of actors } \\
\text { - Program length } \\
\text { - Viewing share } \\
\text { ( } \geq 6 \text { years old })\end{array}$ & $\begin{array}{l}.121 \\
.016 \\
.345^{* *}\end{array}$ & $\begin{array}{r}-.025 \\
-.109 \\
.084\end{array}$ & $\begin{array}{l}.204^{*} \\
.247^{* *} \\
-.077\end{array}$ & $\begin{array}{l}.221^{*} \\
.093 \\
.110\end{array}$ \\
\hline
\end{tabular}

Note: Only genres with significant correlations are presented:

* Correlation is significant at the .05 level (2-tailed).

** Correlation is significant at the .01 level (2-tailed).

(partly due to the viewer's choice), and Dutch television may be even less so since its entertainment function risks being cut back in the future: at the most the viewer watches a mirror of his or her 'own' group. The fact is that public as well as commercial channels make a selection of what they offer their audiences, a process which results in a kind of suboptimal diversity. On top of that, the various audience groups themselves also make a selection, so much so that the diversity they are presented with is de facto reduced even further.

\section{Innovation: the use of cross-medial applications}

Finally, apart from diversity there is yet another aspect of quality, namely innovation. To examine innovation we looked for cross-medial 
Table 6. Cross-medial applications in public and commercial programs (in percentages).

\begin{tabular}{llll}
\hline Application yes/no? & $\begin{array}{l}\text { Public } \\
(\mathrm{N}=227)\end{array}$ & $\begin{array}{l}\text { Commercial } \\
(\mathrm{N}=190)\end{array}$ & $\begin{array}{l}\text { Total } \\
(\mathrm{N}=417)\end{array}$ \\
\hline Yes* & $\mathbf{5 2 . 5}$ & 38.4 & 46.1 \\
No & 47.5 & $\mathbf{6 1 . 6}$ & 53.9 \\
\hline If so, which application(s)? & Public & Commercial & Total \\
& $(\mathrm{N}=119)$ & $(\mathrm{N}=73)$ & $(\mathrm{N}=192)$ \\
\hline Website & 85.7 & 83.6 & 84.9 \\
Phone number* & 20.2 & 17.8 & 19.3 \\
Postal address* & $\mathbf{1 4 . 3}$ & 4.1 & 10.4 \\
E-mail & 10.1 & 11.0 & 10.4 \\
Text messaging* & 1.7 & $\mathbf{1 6 . 4}$ & 7.3 \\
Teletext* & 1.7 & $\mathbf{9 . 6}$ & 4.7 \\
Other & 3.4 & - & 2.1
\end{tabular}

Note: * Significant difference between public and commercial channels (t-test $\mathrm{p}<0.05$ two-sided).

applications, i. e. references to other media, in 417 programs in the sample. Public channels use cross-medial applications in more than half of their programs $(52.5 \%)$, commercial channels considerably less frequently $(38.4 \%)$. Especially Nederland 1 and Nederland 3 can be said to be innovative in this respect. With regard to the nature of these crossmedial applications, the retrieval of information by the viewer is the most important function, both on the public and on the commercial channels. Websites are obviously the most suitable tool for this purpose: about $85 \%$ of cross-medial applications are references to websites. The public channels still use traditional media (such as telephone numbers and postal addresses) slightly more often, while the commercial channels use text messaging more often. We should note that most programs resort to several applications at the same time (Table 6).

In the field of cross-medial applications, too, we find differences according to the genre of programs concerned, both in the kind of application and in its purpose. The retrieval of information is useful for viewers of informative and educational programs so that these programs often refer to websites. However, sports programs as well mention websites strikingly often. Entertainment and fiction programs often refer to telephone and text numbers as viewers are invited to participate in competitions.

The linkage of these data to the viewers' different age brackets reveals that a large number of the viewers of programs using cross-medial applications are over 50 . This most probably follows from the fact that infor- 
mative programs, which are relatively popular among older viewers, are also the programs often using cross-medial applications. With regard to children's programs, the link is explained by the fact that over-50s often watch those programs which often have cross-medial references, doing so alone or together with their children or grandchildren. There is no link between the kind of application and the composition of the audience.

\section{Conclusions and recommendations}

In this article we asked ourselves to what extent and in what way social reality is being constructed through the Dutch public broadcaster compared to its commercial counterparts. How 'virtuously' are the broadcasters portraying social reality when it comes to the visualization of age, ethnicity and gender? What TV channels are doing a lesser or better job, and in what program genres?

At first sight, neither public nor commercial television in the Netherlands appears to be particularly representative of Dutch society. Women, children, senior citizens and ethnic minorities are, generally speaking, underrepresented. However, finding out if the Dutch television (or the public channels or the commercial channels) creates a balanced image of different groups is less simple than it might appear to be.

Things are fairly simple as far as the men/women ratio is concerned: men have a clear majority, whoever the broadcaster and whatever the channel or genre, though Net5 is definitely non-chauvinist and though Nederland 2 mainly puts men on screen. But as far as age and ethnic origin are concerned, the picture is much more complicated. The Diversity Monitor therefore mainly traces the differences between he public and commercial channels at the level of the program genre.

Women are underrepresented in sports items mainly, and in other programs they are presented as common citizens, cast in 'softer' roles or invited to discuss social themes. The most balanced men/women ratio is found in children's programs and in entertainment and fiction. The age structure of the Dutch population is best reflected in children's programs, which are also more 'colorful' than other genres. With respect to the representation of black people, fiction has an above-average score, but that is due to fiction programs from the US. Informative programs and children's programs present an above-average number of people of Mediterranean origin.

The use of cross-medial applications, too, is genre-specific, with the public channels resorting to such applications considerably more than their commercial counterparts. The most frequent application is websites that provide extra information on a given subject. It looks as if the 
public channels try to win their audience by regarding them as citizens, whereas the commercial channels serve their audience by regarding them as consumers: an example is the use of the text messaging facility, which is mainly resorted to in setting up competitions for the viewers.

Comparing open and reflective diversity, we can conclude that the public channels have a low reflective diversity and that commercial channels are more successful in acquainting their audiences with different social groups.

If the results of the Monitor 2005 are compared with the general conclusions of the 2002 version, remembering that in the earlier version the sample included the full range of programs and in the 2005 version prime-time programs only, we find that, in general, little has changed. The men/women ratio and the representation of different age brackets and ethnic groups have largely remained the same, in numbers as well as in the distribution of functions and roles. The 2002 conclusion that the public channels reflected a better image of the different age brackets than their commercial rivals was mainly based on the children's programs of Z@ppelin which were included in the sample. Actually, in the 2005 Monitor as well, children's programs still set an example of reflecting diversity of individuals and groups.

\section{Implications and recommendations for follow-up research}

The 2005 Monitor takes a first step towards a more qualitative analysis by including the roles and functions actors play in television programs and by looking for 'good' and 'bad examples' of diversity in television content, but it has two shortcomings which do not allow us to make sweeping statements. The first is that the coding instrument does not do justice to the characteristics of separate program formats. As it is today, it is a very general measuring tool which does not differentiate between non-fiction programs such as the news, current affairs, game shows, etc., and which also lumps together soaps, reality-TV programs and comedies. The second shortcoming is that the 2005 Monitor takes a purely quantitative approach.

A follow-up study, with more qualitative elements and focusing on argumentations adopted by the different actors under study, is consequently being prepared. One can suggest, for example, a discourse analysis of good and bad practices and interviews with program makers. It is important, after all, not only to focus the study on media contents but also to consider the context and processes underlying media productions. In so doing, the Monitor could evolve into a more effective policy instrument, applicable to all domains of television production and to other media such as radio and the Internet. 
Finally, if in the near future the emphasis is no longer on linear media use but rather on separate programs, then creation and production gain more importance than the packaging on the various channels. Still, program content and the measuring of diversity remain a constant concern. After all, the creation of a more diverse and innovative range of programs requires a continuous awareness by all media workers of the social responsibility they have in a pluralist society. Furthermore, not only in the content of their work must the media reflect cultural diversity, in their staffing policy, too, they should have an eye for the added value of diversity on the shop floor. Moreover, with respect to informative programs, journalists should be supported in their efforts to maintain their editorial independence, so much so that they can develop an effective system of self-regulation and accountability mechanisms. In so doing, the various media professionals will be able to better meet standards of quality.

\section{Notes}

1. During the sample period, between $18.00 \mathrm{hrs}$ and $24.00 \mathrm{hrs}$ and based market share $(17.9 \%)$ while Veronica had the smallest market share $(3.5 \%)$. Special interest channels and regional and foreign broadcasters were excluded from the sample.

2. For each subject, we examined which talking individuals were on screen; one individual could therefore be encoded several times if he or she was shown talking about several subjects.

3. See the channel brand of Net5 on: http://www.tipnl.nl/vervolg.asp?url=http://b2b. sbs.nl

\section{References}

Bardoel, J., d'Haenens, L., and Peeters, A. (2005). Defining distinctiveness. In search of public broadcasting performance and quality criteria. In G. Lowe and P. Jauert (Eds.), RIPE Yearbook: Dilemmas of Public Service Broadcasting (pp. 57-77). Göteborg: Nordicom.

Berger, P. L. and Luckmann, T. (1966). The social construction of reality: A treatise in the sociology of knowledge. Garden City, NY: Anchor Books.

Cole, B. (Ed.). (1981). Television today. New York: Triangle.

Cook, E., Thomas, S., and Wilcox, C. (1994). The year of the woman: Myths and realities. Oxford: Westview Press.

Cottle, S. (Ed.). (2000). Ethnic minorities and the media: Changing cultural boundaries. Buckingham: Open University Press.

Cuilenburg, J. van (2005). On monitoring media diversity, media profusion, and media performance: Some regulator's notes. Communications. The European Journal of Communication Research, 30(3), 301-8.

Cuilenburg, J. van (1999). On competition, access and diversity in media: Old and new. New Media and Society, 1(2), 183-207

Dijk, T. A. van (1991). Racism and the press. London: Routledge. 
Dijk, T. A. van (1983). Minderheden in de media: een analyse van de berichtgeving over etnische minderheden in de dagbladpers [Minorities in the media: An Analysis of the Coverage of Ethnic Minorities in the Daily Press]. Amsterdam: SUA.

Gibson, S. (1996). Understanding media? Available at: http://.raven.ublt.edu/features/ media_ecology/unm/96/gibson1/gibson_1.html

Huysmans, F., De Haan, J., and Van den Broek, A. (2004). Achter de schermen: een kwart eeuw lezen, luisteren, kijken en internetten [Behind the screens: A quarter century of reading, listening, viewing and internetting]. The Hague: Social Cultural Planning Office.

Kahn, K. (1996). The political consequences of being a woman: How stereotypes influence the conduct and consequences of political campaigns. New York: Colombia University Press.

McKee, K. B. (2003). The child as image: media stereotypes of children. In P. M. Lester and S. Dente Ross (Eds.), Images that injure: Pictorial stereotypes in the media (pp.159-166). Westport, CT: Praeger.

McKinsey and Company (2003). Organisatie- en efficiëntieverbeteringen Publieke Omroep. Eindrapport [Organizational change and more efficiency in public broadcasting. Final report]. Hilversum: Publieke Omroep.

McQuail, D. (1992). Media performance. London: Sage.

Peeters, A. L, Jager, R., and Kalfs, N. (2005). Wie kijkt? De meting achter de kijkcijfers [Who's watching? The measurement behind the figures]. Amsterdam: Boom.

Scientific Council for Government Policy (WRR) (2005). Focus op functies: uitdagingen voor een toekomstbestendig mediabeleid [Media policy for the digital age]. Amsterdam: Amsterdam University Press.

Selm, M. van and Peeters, A. L. (2005). Additional channels in Dutch television genres. Paper presented at the 55 $5^{\text {th }}$ annual ICA Conference, New York, 26-30 May 2005.

Smythe, T. C. (2003). Growing old in commercials: not always a laughing matter. In P. M. Lester and S. Dente Ross (Eds.), Images that injure: Pictorial stereotypes in the media (pp. 167-172). Westport, CT: Praeger.

Souchon, M. (1994). L'avenir de la télévision publique. Communication et Langages, $100-101,27-39$.

Sterk, G. and Dijk, B. van (2003). Monitor Diversiteit 2002 [Monitor diversity 2002]. Hilversum: Publieke Omroep.

Ter Wal, J. (Ed.). (2002) Racism and cultural diversity in the mass media. An overview of research and examples of good practice in the EU member states, 1995-2000. Vienna: European Monitoring Centre on Racism and Xenophobia. Available at: http://www.eumc.eu.int.

Wurff, R. Van der (2004). Supplying and viewing diversity: the role of competition and viewer choice in Dutch broadcasting. European Journal of Communication, 19(2), 215-37. 